\title{
Culture and the Near-Death Experience: Comments on Keith Augustine's "Psychophysiological and Cultural Correlates Undermining a Survivalist Interpretation of Near-Death Experiences"
}

\author{
Allan Kellehear, Ph.D. \\ University of Bath, UK
}

ABSTRACT: This paper is a sociological commentary on the leading paper by Keith Augustine. It discusses the relationship between social expectations and culture as well as extending the discussion about the possibility that neardeath experiences may not be a singular entity. I suggest there are sound grounds for developing a typology of experiences that have different and or overlapping causes and phenomenology.

KEY WORDS: near-death experiences; cultural variation; sociology; typologies; social expectations.

Keith Augustine's arguments in favor of physiological explanations of the near-death experience (NDE) are a strong, critical, and welcome addition to the ongoing debate about how to explain NDEs. His philosophical position is obviously empirical and material but it is also largely inclusive; he does not foreclose, much less dismiss, the possibility that NDEs may suggest survival possibilities even if he does believe these unlikely and remote. And he is right to point out the overstated and uncritical literature coming from New Age writers and

\footnotetext{
Allan Kellehear, Ph.D., is Professor of Sociology at the University of Bath, Bath, UK. Requests for reprints should be addressed to Professor Allan Kellehear, Centre for Death and Society, Department of Social and Policy Sciences, University of Bath, Bath BA2 7AY, United Kingdom; e-mail: a.kellehear@bath.ac.uk.
} 
their sympathizers, some of whom cloak their bias in academic credentials and affiliations. There is a longstanding tension between the skeptics and the credulous, and reading their respective exaggerated interpretations of the data is both tiresome and more than a little annoying.

I welcome several of his arguments and insights: for example, his rejection of the continually recycled sociological myth that children somehow escape from cultural conditioning and so represent socially "uncontaminated" NDEs. This is untrue, and can never be true, for experiences cannot be understood separate from the language that describes them, at the time, or retrospectively as in the cases of childhood NDEs. I also welcome Augustine's insistence on our continuing pursuit of precise physiological explanations for the NDE, for clearly, NDEs must have at least physiological correlates and prompts. Why should NDEs be exempt when attachment, grief, depression, anxiety, smiles, and exhilaration are not? But social and psychological experiences such as happiness, bereavement, or mystical experiences are not exhausted by their physiological underpinnings because we are also aware of the role culture plays in shaping, prompting, or moderating both physiological and even pharmacological processes. Some have long suggested - from religious studies, theology, and even some quarters of psychiatry and psychology - that supernatural factors may further shape, prompt, or moderate the social and psychological factors.

The modern debate is always about the mix of influences, and sometimes their validity, particularly for supernatural factors. But the debates are always useful to have, all sides modifying, tightening, or strengthening their respective arguments, usually around the same pool of evidence. That situation, as unfashionable as it sounds, is called "scholarship" and it is this very stuff that takes all good scientific thinking forward. I think Augustine's arguments serve us well here. I agree with Augustine when he remarks that "our best evidence shows that regardless of how NDEs are ultimately explained, a survivalist explanation will not do," but I would hasten to add "will not do alone."

No doubt other commentators will address the medical aspects of Augustine's arguments, so I will confine my remaining remarks to his reanalysis of the cultural data on NDEs. First of all, I think Augustine minimizes both the differences between features of the NDE in general and those we might predict from social expectation. For example, 
Augustine argues that "afterlife vistas ... - aside from being a better place to live - appear exactly like the world of the living." This is not true. Many NDErs report colors they have not seen on Earth, or androgynous supernatural figures they would not expect to see, especially in a "religious figure" in Western NDEs. Melanesian NDErs would not expect to see the "floating" suspended-in-the-air huts reported in their NDEs or be expecting to fly to see relatives in America.

One of the consistently reported "features" of the NDE is its ineffable nature. This refers to common difficulties in putting into meaningful words the colors, sounds, knowledge, or even appearances of things encountered in the NDE. In turn, this suggests strong caution in interpreting all NDEs, not the least those from nonWestern sources. The use of language cannot be separated from the recounting of experience, but the qualification that must accompany such cultural and linguistic analyses is that we might be dealing with major problems of internal reliability and validity as each NDEr struggles to throw words at unfamiliar experiences and sensations - the very opposite of the theoretical problem of social expectations.

Nevertheless, encountering supernatural and deceased beings, otherworld vistas, and perhaps a darkness, do seem to be crosscultural features associated with NDEs. Yes, these are general, and they are what you would expect from people claiming some sort of encounter with death or dying. But that observation does not lessen their significance or validity. People expect to be happy on their wedding day, and indeed most probably are, and although this fact plays an important role in the "reality" of the happiness, it does not create the events in question. Clearly, expectation has a role to play in NDEs as in experiences at weddings, but just as clearly there are many personal and public experiences at weddings and during NDEs that are unexpected. I think Augustine actually argued this very point elsewhere, but he did not always hold this more nuanced view consistently. Often Augustine equates culture with expectation, and where expectation does not oblige, he suggests physiological influence. Like Augustine, I think the unexpected events, experience, and features of NDE are as crucial to any broad, eventual explanation as those attributed to expectation, but we need to be careful not to be too literal here.

For example, Augustine rejects my linking NDE imagery with childhood stories as being a bit far-fetched. If I were making that link 
literally I would agree. However, my purpose in making that connection was to demonstrate, through one example, how socialization of identity can occur quite early in human development (through children's stories) but also how those stories and countless others in adult literature and other media are reflected in a consistent style of interpreting our world in terms of rebirth, trial, survival, and transformation. These longstanding storylines in myth, legend, and modern literature may play an important role in how NDEs are structured as accounts of unexpected journeys and equally unexpected returns. In these ways, the interpretive structure, if not the content, of NDE narratives may be attributable, in part, to those broader cultural influences. Alice in Wonderland (Carroll, 1865) does not account for NDE motifs; please give me some credit for a wider reading of cultural influences and NDEs!

Augustine writes that "there is no reason to assume that different NDErs are simply using different labels to describe the same experience," but there is in fact a reason. People often use different labels to describe the same experience - and not only different labels but also different stories in describing the same experience. For some people too much is not enough; for others "not enough" is too much. A sexual encounter between two adults at an office party might be described by one of these persons as a one-night stand, but by the other as a rape. If such differences in language and storyline did not regularly emerge from human beings we would have no use for courts and their trials and juries, semiotic traditions in literature, or psychoanalysis or counseling. Experience alone does not predict the story that will emerge from it because different interpretations, personalities, and social and cultural backgrounds will mediate, some even say help "construct" or "re-make" the experience itself.

These remarks notwithstanding, I nevertheless agree with Augustine that some NDErs may actually be having very different experiences. But clearly there are limits to how literal we should take NDE accounts. Augustine argues that instead of saying NDErs are encountering the same thing but labeling it differently, perhaps we should "take each at his word instead of assuming that both are encountering the same darkness in order to fit our artificial NDE models." This is an important point to hold, but not eternally. Augustine wants us to agree to this only for a limited time, just for individual features of $\mathrm{NDE}$ as described by the NDEr. If we were to take our NDErs on their word overall we would be compelled to accept 
their own oft-heard conclusion that NDEs are a glimpse of the afterlife, obviously not a conclusion Augustine wants us to embrace!

However, there may indeed be an actual diversity of NDE features, but I do not believe that diversity of NDEs of itself makes the arguments for survival, for whoever wants to make them, less convincing. Perhaps there really are several "otherworlds"; there are several "worlds" here, so why not there? Even Augustine himself accepts this in principle, admitting later in his article that "It is entirely possible that an afterlife exists but that NDEs are not glimpses of it - a view similar to the Buddhist belief that the dying pass through several illusory bardo states generated by their own minds before entering the 'real' afterlife (Fox, 2003)."

This brings me to what I believe is Augustine's most important positive contribution in his reflections about culture and NDEs. Augustine moves backwards and forwards over a complex and diverse terrain where, on the one hand, he is trying to emphasize the methodological implications of crosscultural differences and Western similarity, whereas on the other hand, he struggles to be theoretically inclusive, attempting to bring all this diversity under one multifaceted rubric of biopsychosocial explanation. This evenhanded attempt is both the strength and provocative nature of his contribution. This is not a reductionistic strategy, at least in my eyes. But it fails to convince me, because he brings multiple explanations to service what he seems often to imply is a singular entity. But what if we are not dealing with a single entity?

I think, and Augustine's analysis might equally suggest, that we may actually be dealing not with one NDE, but many. Perhaps we are not, nor ever have been, talking about one type of NDE (or OBE) but rather several types of NDE. Some NDEs may indeed be outright hallucinations, some may have hallucinatory elements, and some may not fit these models at all, calling up instead other models of consciousness or even religious experience.

Some years ago I was impressed at the recounting of a so-called "NDE" by the eminent philosopher A. J. Ayer. For my admittedly rather academic familiarity with the medical literature on hallucinations and delusions, the phenomenology of this "NDE" had all the features one would expect from a hallucination. Rising levels of uremic toxicity in the bloodstream commonly associated with renal failure often create frightening or morbidly dark images, and Ayers had suffered both at the time. Other NDE reports are so vague and general 
that it is equally possible to entertain both simple psychophysiological explanations and mystical ones; there is simply insufficient detail to argue the toss. Yet other individual cases of NDEs do seem to suggest more. Some cases, for example, impress with empirical knowledge of events and actions that took place while the experiencer was unconscious. These cases suggest dissociative phenomena beyond simple internally generated imagery, and may even suggest new models of perception for the unconscious person that we are only just beginning to understand. Sometimes it is more incredible to believe the patchy reductionistic explanations for why people know things they should not when unconscious than to simply take them "at their word," to take Augustine's ironic advice, and work from there.

Augustine's suggestions for the two important directions for future sociological research are absolutely correct. We do need to search for more compelling links between NDE motifs and cultural sources and we need more nonWestern NDEs with larger sample sizes. He is also right to warn us against the all-too-common tendency to polarize each other over extreme and overstated arguments about the NDE. Serious research into NDEs resembles serious research everywhere: it is methodological diverse and epistemologically inclusive, or at the very least, epistemologically tolerant. No one researching the human immunodeficiency virus (HIV) seriously believes that an understanding and medical solution to the problem of acquired immune deficiency syndrome (AIDS) is found exclusively in studying the virus. Yes, the bench science study of the virus "causing" AIDS is essential; but those facts will neither help us stop its spread nor administer its cure when and if we ever find one. The public health science of AIDS is to recognize the absolutely crucial role of sexual and drug-using behaviors and attitudes as well as those generated by poverty in places such as Africa or Southeast Asia. Multiple frames of analyses are critical in understanding human behavior, and those who choose to dismiss other ways of seeing strengthen their gaze at the cost of narrowing and decontextualizing it.

There must be a biological mechanism for NDEs. Whether all NDEs are to be understood only in these terms will depend on an evolving understanding of its possible typology. The credibility of any evolving typology will depend on how sensitive we are to the different internal psychological and cultural subtleties that are inevitably associated with all altered state of consciousness. The ultimate inclusiveness of these patterns - whether these will privilege only bodily, psycholog- 
ical, and cultural patterns or will recognize more to our experience than these platforms - will depend on how persuasive the empirical evidence is that could suggest something more. Until that time we are left largely with arguments, and Augustine's contribution has been a helpful turn around this very old territory.

\section{References}

Carroll, L. [Dodgson, C. L.]. (1865). Alice's adventures in Wonderland. London, England: Macmillan. 